\title{
Seasonal variation of cancer mortality in Hungary between 1984 and 2013
}

\author{
KATALIN VIRÁG ${ }^{1} \&$ TIBOR ANDRÁS NYÁRI² \\ ${ }^{1}$ Bolyai Institute, and ${ }^{2}$ Department of Medical Physics and Informatics; University of Szeged, Hungary
}

\begin{abstract}
Aims: Despite decreasing trends, Hungary is the leader in cancer mortality among European countries. We examined the seasonal variation of cancer mortality in Hungary between 1984 and 2013. Methods: Hungarian monthly cancer mortality and population data were used in the analysis. The Walter-Elwood method was used to determine seasonal variation in both mortality rates and proportionate mortality. Results: Significant winter-peak seasonality was found in all-cancer mortality. A similar seasonal trend with a peak from November to January was observed in death rates from colorectal, lung, female breast, prostate, bladder, brain, lymphoid and hematopoietic cancers. However, no more cyclical variation was identified in the mortality rates from other cancers. In addition, significant seasonal variation in proportionate mortality was shown for all cancer sites examined, with a peak in August or September. Conclusions: This study presents the seasonality pattern of different types of cancer mortality which might be related to environmental factors (e.g. infections).
\end{abstract}

Key Words: Cancer, mortality, proportionate mortality, seasonal variation, epidemiology, Hungary

\section{Introduction}

All-cancer mortality rates in both sexes have been high in the last three decades in Hungary. The most common causes of death from cancer in the last 30 years have been cancers of the lung (7586 deaths/ year on average), followed by colorectal (4608), stomach (2348) and female breast (2174) cancer. These are also the leading causes of death from cancer in the European Union. However, among the countries in the European Union in 2012, Hungary recorded one of the highest standardised death rates from oral cavity and pharynx, colorectal, pancreatic, larynx and lung cancers and leukaemia [1].

The seasonal variation in the aetiology of a disease can shed light on the effect of certain environmental factors (e.g. the role of infections). However, cyclical variation is rarely investigated in mortality. Our aim was to investigate the seasonal pattern in cancer mortality in Hungary between 1984 and 2013.

\section{Methods}

The Hungarian monthly cancer mortality and population data for the period 1984-2013 were supplied by the Hungarian Central Statistical Office [2]. The underlying causes of death were classified according to the International Classification of Diseases (ICD), Ninth and Tenth Revisions. The major cancer sites under examination together with ICD-10 codes are as follows: all cancers (C00-C96), lip, oral cavity and pharynx (C00-C14), oesophagus (C15), stomach (C16), small intestine (C17), colorectum (C18C21), liver and intrahepatic bile ducts (C22), gallbladder, other and unspecified parts of the biliary tract (C23-C24), pancreas (C25), trachea, bronchus and lungs (C33-C34), female breasts (C50), cervix uteri (C53), corpus uteri (C54), ovaries (C56), prostate (C61), bladder (C67) and brain (C71), as well as malignant neoplasms of the lymphoid, hematopoietic and related tissues (C81-C96).

Correspondence: Tibor András Nyári, Department of Medical Physics and Informatics, University of Szeged, H-6720 Szeged, Korányi fasor 9, Hungary.

E-mail: nyari.tibor@med.u-szeged.hu

Date received: 12 May 2017; revised: 29 September 2017; accepted: 10 October 2017

(C) Author(s) 2017

Reprints and permissions: sagepub.co.uk/journalsPermissions.nav

DOI: $10.1177 / 1403494817744074$

journals.sagepub.com/home/sjp

(SSAGE 
Seasonal trends on deaths from cancer in aggregated monthly data were investigated using generalised linear models [3] and the Walter-Elwood method [4]. Seasonality in proportionate mortality and in crude mortality rates was also analysed. Monthly deaths were adjusted for month length. Monthly population estimates were calculated on the basis of the monthly number of births and deaths supplied by the Hungarian Central Statistical Office. Proportionate mortality is calculated as the fraction of all deaths due to a specific cause. The monthly average and the total number of cancer deaths were also calculated for each cause of death as descriptive statistics. Winter-tosummer ratios for all causes of death were calculated as the total number of deaths in December, January and February divided by the total number of deaths in June, July and August.

$p$-Values $<0.05$ were considered to be statistically significant. All analyses were conducted with Stata Statistical Software v9 (StataCorp LP, College Station, TX).

\section{Results}

\section{Seasonality in cancer mortality rates}

Overall, 959,307 deaths from malignant neoplasms were registered in Hungary during the study period. The highest mortality of 227,581 was found from lung cancer, and the smallest from cancer of the small intestine (2073). The monthly and the total numbers of deaths from different types of cancer are summarised in Table I.

The Walter-Elwood method indicated significant seasonality in the mortality rates from all malignant neoplasms combined with a winter peak $(p<0.001$, peak in December; Figure 1(a)). A similar cyclical variation was observed in the mortality rates from cancers of the trachea, bronchus and lungs $(p<0.001$, December), and bladder ( $p<0.001$, December). A winter peak was also found in the mortality rates from female breast $(p<0.001$, January $)$ and prostate $(p<0.001$, January) cancers and cancers of the lymphoid, hematopoietic and related tissues $(p<0.001$, January). Colorectal and brain cancer deaths were significantly the highest in November $(p=0.016$ and 0.002 , respectively). The mortality rates from cancer of the oesophagus were significantly the highest in August $(p=0.006)$. However, no more cyclical variation was identified in the mortality rates from other cancers (Table I). In spite of the higher numbers of deaths from gastric (stomach) cancer, no evidence of a significant cyclical trend in mortality rates was found $(p=0.603)$.

Negative binomial regression models confirmed the findings reached with the Walter-Elwood method.
All models provided a reasonable fit using the deviance goodness-of-fit test (Table I). The winter-tosummer ratio varied from 0.951 (cancer of the oesophagus) to 1.089 (malignant neoplasms of lymphoid, hematopoietic and related tissues; Table I).

\section{Seasonality in proportionate mortality from cancer}

The all-cancer proportionate mortality rates have varied from $21.4 \%$ to $25.1 \%$ in January and in September, respectively. Walter-Elwood tests and negative binomial regression models on proportionate mortality indicate that there is significant evidence of seasonality for all cancer sites under examination $(p<0.001)$, with a peak in August or September. Figure 1(b) shows the monthly all-cancer proportionate mortality.

\section{Discussion}

\section{Main findings}

Either significant late autumn-winter peak seasonality or non-cyclical variation was found in the mortality rates from the main cancer sites under examination. Nevertheless, significant seasonality was found in the proportion of deaths from all cancers detected and in the main cancer sites under examination, with a peak in August and trough in February.

\section{Strengths and weaknesses of the study}

Our data were obtained from published tables and civil registers, which could have been influenced by a certain simplification of the categorisation and by the difference in the two revisions of the ICD that were introduced in Hungary during the study period. Additionally, minor changes occurred in the structure of the reported data. However, the Walter-Elwood method was used on aggregated mortality data with a long study period of 30 years. Moreover, negative binomial regression models confirmed the findings from the Walter-Elwood tests. An investigation of seasonality stands as an important component in understanding the aetiological description of certain diseases.

\section{Comparison with other studies}

Previous studies have demonstrated a link between season of diagnosis and survival for many cancer types in several European populations. Moreover, Ho et al. [5] showed that seasonality depends on latitude. However, seasonal variation in cancer mortality is rarely investigated. It is already known that overall 


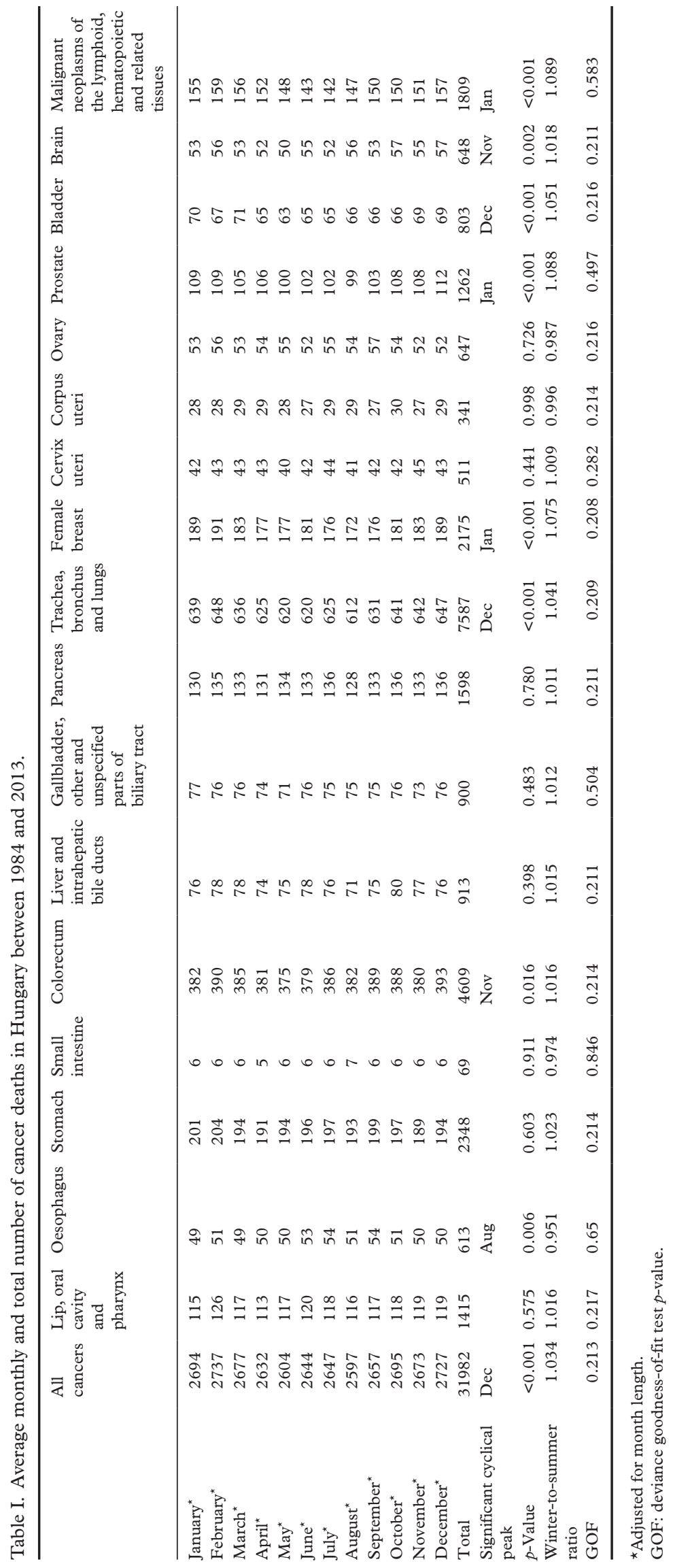




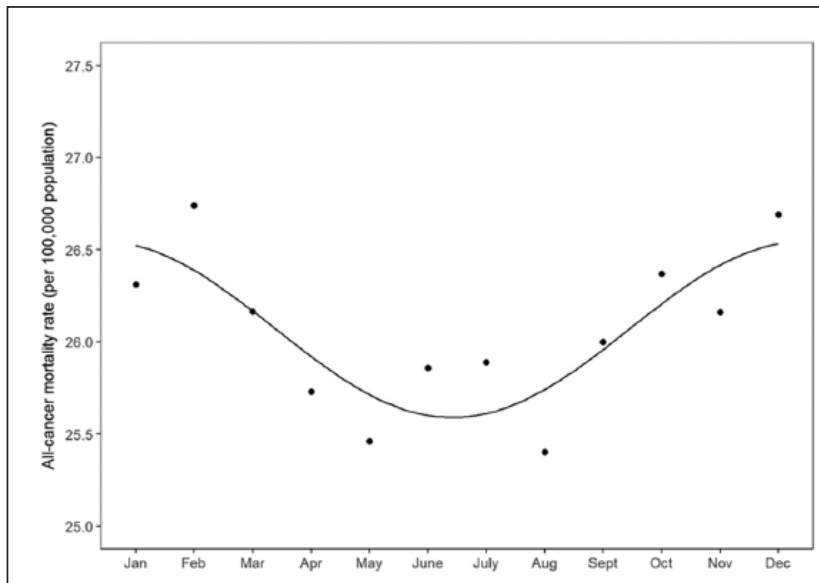

(a)

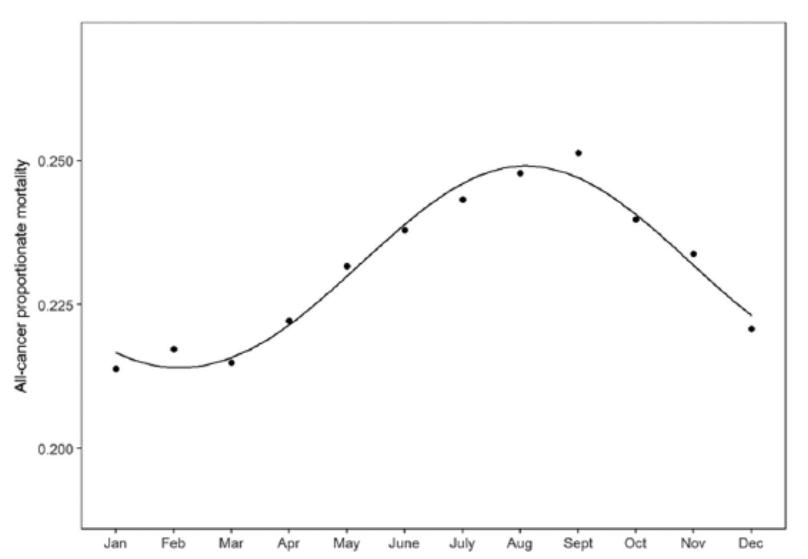

(b)

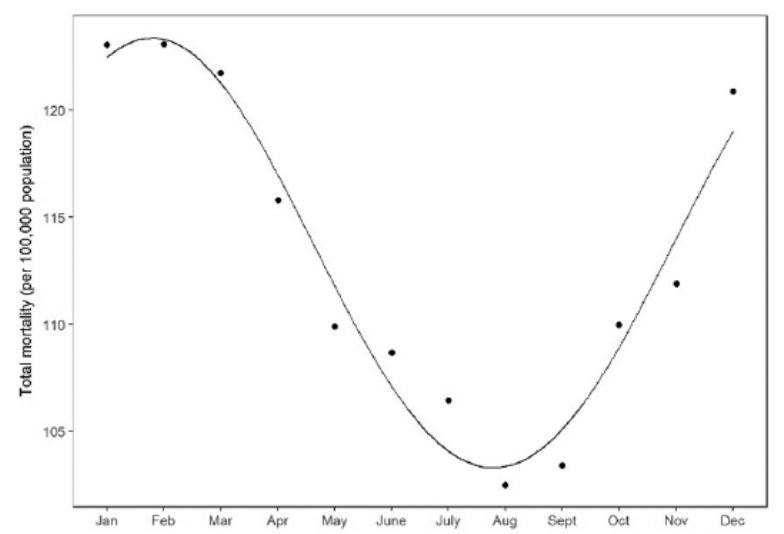

(c)

Figure 1. (a) Seasonal variations in monthly all-cancer mortality rates (per 100,000 population) in Hungary between 1984 and 2013. (b) Seasonal variations in monthly all-cancer proportionate mortality in Hungary between 1984 and 2013. (c) Seasonal variations in monthly total (all cause) mortality rates (per 100,000 population) in Hungary between 1984 and 2013.

mortality is higher in cooler than in warmer months in Europe [6]. Nevertheless, Marti-Soler et al. [7] found little or no seasonal variation in cancer mortality in most countries. Nakaji et al. [8] reported major influences of seasonal change on the overall causes of death in Japan, with the highest rates in winter, but not on mortality from cancer. Similarly, an increase in deaths from non-cancer during winter was reported in sub-tropical Asian cities [9]. However, Medenwald and Kuss [10] observed noticeably more deaths from cancer than expected in the week preceding Christmas.

In our study, significant winter peak seasonality was found in mortality rates from all cancer. Additionally, significant cyclical variation on proportionate mortality was observed for all cancer sites examined, with a peak in August or September. The proportionate mortality rates varied from $21.4 \%$ to $25.1 \%$ in January and September, respectively, and yielded a summer peak in the proportionate cancer mortality. This inverse seasonal cycle must be the result of the very same variation, with a much stronger variation for non-cancer mortality than for cancer mortality (Figure $1(a)-1(c))$. However, both seasonal patterns are interesting and informative to potentiate prevention.

De' Donato et al. [11] reported that an increase was detected in the effect of high temperatures for all causes of death considered in Budapest (and in eight other European cities), although statistical significance was only reached for cardiovascular causes. Furthermore, in Hungary, the warmest period of the year is late July and early August, though higher extreme temperatures were registered in August [12]. By contrast, the excess winter mortality can be attributed to environmental factors such as air pollution, residential heating and seasonal infections [13].

Although seasonal patterns in all-cancer mortality have already been examined by other investigators, as far as we are aware, this is the first epidemiological study to report the effect of seasonality in mortality at different cancer sites. 


\section{Conclusions}

Our ecological study presented the seasonality pattern of some cancer mortality which might be related to environmental factors (e.g. infections, temperature). We speculate that infectious diseases may increase the risk of mortality among immune deficient patients. However, further cohort studies are required to explain the seasonal pattern of mortality due to cancer.

\section{Declaration of conflicting interests}

The authors declare that there is no conflict of interest.

\section{Funding}

The authors disclosed receipt of the following financial support for the research, authorship, and/or publication of this article: Katalin Virág and this study were supported by the European Union and the State of Hungary, co-financed by the European Social Fund within the framework of the TÁMOP4.2.4.A/2-11/1-2012-0001 'National Excellence Programme' and EFOP-3.6.1-16-2016-00008.

\section{References}

[1] Ferlay J, Steliarova-Foucher E, Lortet-Tieulent J, et al. Cancer incidence and mortality patterns in Europe: estimates for 40 countries in 2012. Eur f Cancer 2013;49:1374-1403.

[2] Hungarian Central Statistical Office. Demographic yearbook 1984-2013. Budapest, Hungary: Hungarian Central Statistical Office.
[3] Stolwijk AM, Straatman $\mathrm{H}$ and Zielhuis GA. Studying seasonality by using sine and cosine functions in regression analysis. I Epidemiol Community Health 1999;53: 235-238.

[4] Walter SD and Elwood JM. A test for seasonality of events with a variable population at risk. Br $\mathrm{f}$ Prev Soc Med $1975 ; 29: 18-21$.

[5] Ho A, Gabriel A, Bhatnagar A, et al. Seasonality pattern of breast, colorectal, and prostate cancer is dependent on latitude. Med Sci Monit 2014;20:818-824.

[6] Healy JD. Excess winter mortality in Europe: a cross country analysis identifying key risk factors. $\mathcal{F}$ Epidemiol Соттиnity Health 2003;57:784-789.

[7] Marti-Soler H, Gonseth S, Gubelmann C, et al. Seasonal variation of overall and cardiovascular mortality: a study in 19 countries from different geographic locations. PLoS One 2014;9:1-13.

[8] Nakaji S, Parodi S, Fontana V T, et al. Seasonal changes in mortality rates from main causes of death in Japan. Eur $\mathcal{F}$ Epidemiol 2004;19:905-913.

[9] Goggins WB, Chan EYY, Yang C, et al. Associations between mortality and meteorological and pollutant variables during the cool season in two Asian cities with subtropical climates: Hong Kong and Taipei. Environ Heal 2013;12:1.

[10] Medenwald D and Kuss O. Deaths and major biographical events: a study of all cancer deaths in Germany from 1995 to 2009. BMF Open 2014;4:e004423.

[11] De' Donato FK, Leone M, Scortichini M, et al. Changes in the effect of heat on mortality in the last 20 years in nine European cities. Results from the PHASE project. Int $\mathcal{F}$ Environ Res Public Health 2015;12:15567-15583.

[12] OMSZ, www.met.hu/en/eghajlat/magyarorszag_eghajlata/ altalanos_eghajlati_jellemzes/homerseklet/ (2017, accessed May 12, 2017).

[13] The Eurowinter Group. Cold exposure and winter mortality from ischaemic heart disease, cerebrovascular disease, respiratory disease, and all causes in warm and cold regions of Europe. Lancet 1997;349:1341-1346. 